\title{
Genetics of Keloid Scarring
}

Alia Sadiq, Nonhlanhla P. Khumalo, and Ardeshir Bayat

\section{Contents}

8.1 Background - 62

8.2 HLA Immunogenetics - 62

8.3 Linkage - 63

8.4 Large-Scale Population Single-Nucleotide Polymorphism (SNP) - 64

8.5 Gene Expression - 65

8.6 MicroRNAs (miRNA) -65

8.7 Long noncoding RNA (IncRNA) - 65

8.8 Small Interfering RNA (siRNA) - 65

8.9 Microarray Analysis - 70

8.10 Epigenetics - 71

8.10.1 Methylation - 71

8.10.2 Histone Modifications - 71

8.11 Mutations - 72

8.12 Copy Number Variation - 72

8.13 FISH (Fluorescence In Situ Hybridization) - 72

8.14 Conclusions - 72

Further Readings/Additional Resources - 73 


\subsection{Background}

Overview Keloid disease (KD) is an aesthetically and physically distressing skin disorder [74]. KD is considered a benign tumor of the dermis that develops as a result of a dysregulated healing response to cutaneous wounding [88]. Phenotypically, it is an exophytic proliferative fibrous growth of ill-defined etiopathogenesis [15, 17]. Keloid scarring is an enigma and a challenge to clinicians especially dermatologists and surgeons [87], due to its poor response to clinical management [88].

Keloids are reported to have a high incidence in darker skin races and certain ethnicities of AfroCaribbean origin [4]. The incidence of keloid cases is $16 \%$ in black Africans [15] and keloid predominance in females as compared to the males might be due to more piercing trends in females [82].

This benign skin disease can either occur sporadically, or can exhibit a familial pattern. Keloid disease is considered a genetic disease due to a strong genetic susceptibility to keloid formation as it occurs predominantly in people of African and Asian descent, runs in families, and has been found in twins. However, a well-defined comprehensive mode of inheritance still remains unknown due to insufficient studies to uncover the genetic basis of keloid formation. Nevertheless, inheritance patterns for X-Linked or autosomal dominant trait have been found in families with keloids [71]. Although no specific genes have been identified, that is directly linked to the development of keloids, a few genetic loci have been reported to have a potential role in disease susceptibility. A study conducted in a Japanese population revealed four potential SNPs (single-nucleotide polymorphisms) in three chromosomal regions [76]. Anatomical sites affected with KD also vary in different keloid-prone families [9]. Keloid scarring may comprise of multiple genes, and affected individuals could possess variable genetic susceptibility for a set of genes or gene mutations associated with keloid phenotype [4]. Association studies for keloids such as gene polymorphisms and mutations have been conducted for some genes including SMAD3, SMAD7, and SMAD6, TGF- $\beta 1-3$, and TGF- $\beta$ RI-III to investigate the respective genetic basis of disease pathology. Some genetic networks such as cellular apoptosis, MAPKs, TGF- $\beta$, IL- 6 and PAI- 1 have also been studied in keloid pathology $[8,10-13,15,99]$ and also found associated with immunogenic processes as well as other biological pathways (PAI-1, Bcl-2, p53, and collagen deposition) [88]. Complexity and differences in the inheritance modes and familial keloid scarring reflect the variability and heterogeneity in genetic susceptibility, family history, twin genetic makeup, inheritance patterns, linkage, genetic associations, variation in gene expression and respective gene pathways, HLA (human leukocyte antigen) polymorphism, epigenetics, and ethnic populations [88]. Currently, none of hypothesized mechanisms can directly explain the disease pathology. Moreover, the lack of effective treatment options underlines the lack of understanding about disease process and complex and multivariable pathogenesis [74].

Objectives The objectives of this review are to investigate the evidence related to the genetic basis and its association with keloid disease. A comprehensive literature search was performed using PubMed, Google Scholar, CNKI and Embase databases, by applying combinations of relevant MeSH (Medical Subject Headings) words as title. The key search terms included "Keloid, HLA immunogenetics, Linkage, and Large scale population SNP analysis." The appropriate keywords included "Keloid, RNA Sequence analysis, Microarray, Micro RNA, Methylation, Mutation, Epigenetics, and FISH." All retrieved records were compiled in the study for comprehensive review and evaluated based on significance, methodology, evidence, and reproducibility (•Fig. 8.1).

\subsection{HLA Immunogenetics}

Human leukocyte antigen (HLA) is the only complex genetic polymorphic system present on the 6th chromosome (short arm) and is involved in presentation and processing of peptide antigens via HLA class I and II [23]. The association or involvement of HLA in keloid etiology remains elusive as the pathology of dermal fibrosis and poor wound-healing remain ill understood [74].

A study conducted in Caucasians and Chinese Hans populations demonstrated the involvement of immunogenetics (HLA alleles) in keloid etiology. Generally, environmental exposure during the wound-healing process alters the antigen presentation and expression levels of HLA molecules that trigger respective immune response including prolonged inflammation and subsequent release of profibrotic cytokine/chemokines contributing to the excessive extracellular matrix (ECM) deposition, leading to the development of the keloid phenotype. The presence of (altered) immune cells in keloids, provides the insight into the disease pathology. Variable/altered gene and protein expression in keloids supports the contribution of a dysregulated immune system for disease progression or development [4]. The association of immunogenic molecules with the keloid phenotype, has been shown by a study, in which peripheral blood mononuclear cells of keloid patient exhibited increased expression levels of HLA-DR, -DQ, -DP and CD1a molecules in keloid patients [57].

The association of keloids with HLA-I alleles, has been studied in Chinese Han population (192 patients and 252 healthy individuals) to find out the HLA status 


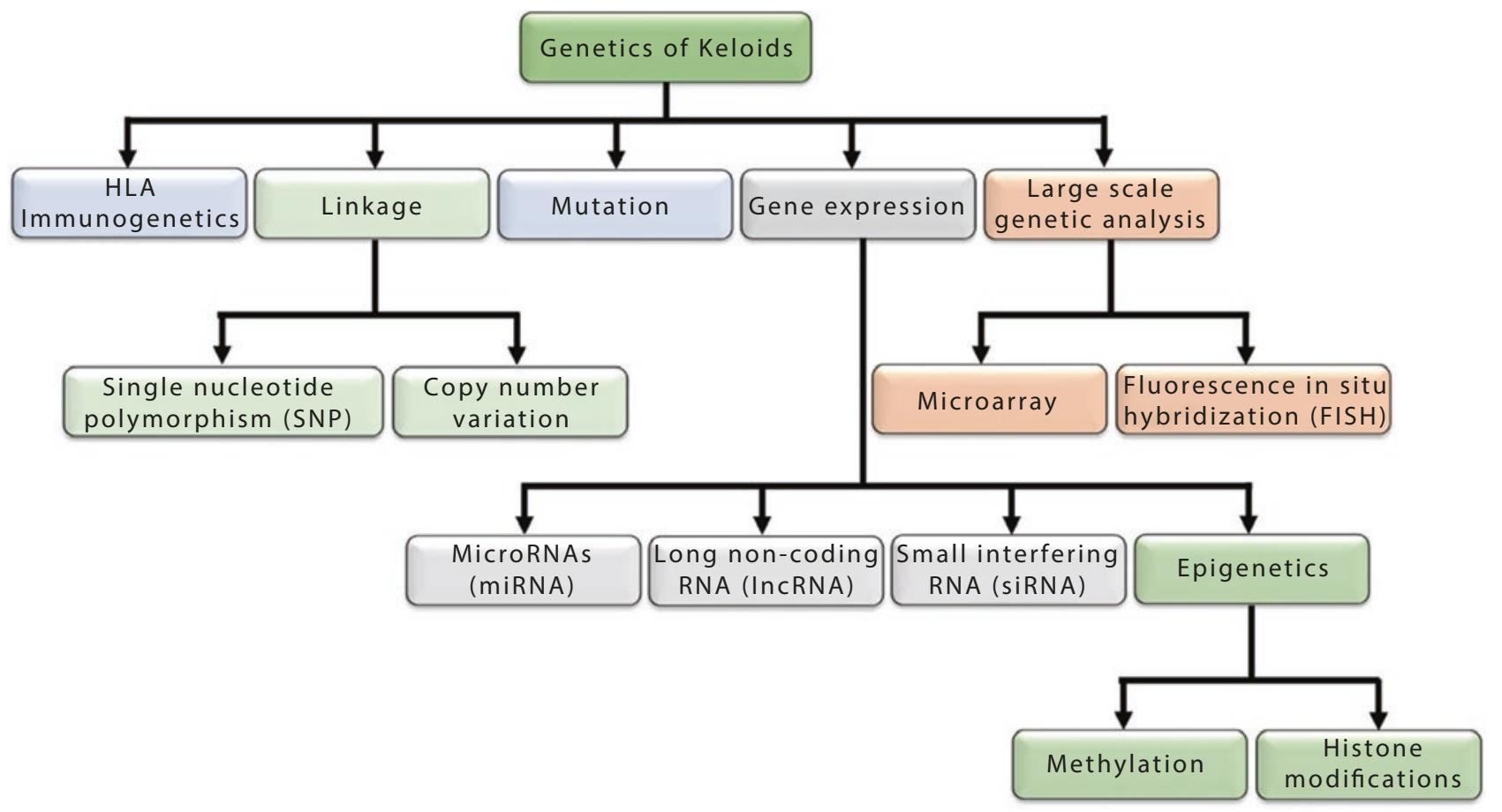

- Fig. 8.1 Association of various genetic elements with keloid development

as a potential contributor to the keloids formation. The frequencies of HLA-A $* 03, \mathrm{~A} * 25, \mathrm{Cw} * 0802$, and $\mathrm{B} * 07$ were significantly high in keloid group but, the frequency of HLA-A*01 was highly decreased in comparison with healthy individuals. This study described high risk haplotypes $(\mathrm{A} * 03-\mathrm{B} * 07, \mathrm{~A} * 25-\mathrm{B} * 07, \mathrm{~A} * 03-\mathrm{CW} * 0802$, $\mathrm{A} * 25-\mathrm{CW} * 0802$, and $\mathrm{B} * 07-\mathrm{CW} * 0802$ ) as contributing components in keloid formation. Interestingly, keloid site specificities, number, severity and details of family inheritance were also associated with specific alleles of HLA class. It shows that maybe these alleles are linked (linkage) with genes, which are responsible for keloid susceptibility [65]. Of note, HLA-I alleles $(A * 01$, $\mathrm{A} * 03, \mathrm{~A} * 25, \mathrm{~B} * 07$ and $\mathrm{Cw} * 08: 02$, HLA-DQA1 and DQB1) previously associated with KD in participants of Chinese ethnicity were shown to have no significant differences in allele frequencies in keloid cases from Jamaican Afro-Caribbean ethnic group [4].

Keloid patients were also found to have an association with blood type A and human leukocyte antigens HLAB14, HLA-B21, HLA-BW35, HLA-DR5, HLA-DRB1, HLA-DQA1, HLA-DQB1, and HLA-DQW3 [78, 88, 110]. The association of HLA-I histocompatibility antigens, patient's family history with earlobe keloids pathology, has been studied in females of Black ethnic group. This study revealed some factors that appear in high frequency and acts as a risk factor when associated with: (i) HLA-A 9, (ii) HLA-A 23, (iii) HLA-Aw 34, (iv) HLA-Cw 2 antigens, history of (v) hypertension and (vi) post-ear piercing infection [29].
Association between HLA-DRB1 phenotype and keloid etiology has been studied in Caucasians populations of Northern European origin (keloid cases $n=$ 67 , control $n=537$ ). It was revealed that frequency of HLA-DRB1*15 was high $(38.8 \%)$ in Caucasians keloid cases, which appeared as a risk factor of developing KD following injury [17]. Frequencies of serologically detectable HLA antigens, i.e., HLA-B14 and HLA-Bw16, were subsequently found to be more $(25 \%)$ common as compared to the control, which further suggests that, the individuals having HLA-B14 or HLABw16 phenotype may be at risk for keloid formation [51].

It seems that most likely there is an association between alleles of HLA class and/or shield against dermal fibrosis, because allele loci (DQ and DR) from class II is a promising genetic marker owing significance contribution in poor wound healing and fibrosis [74]. All of these investigations deliver a strong statement about significant involvement of immunogenic component in keloid pathogenesis [19, 23].

\subsection{Linkage}

The prevalence of KD in identical twins, in families, in certain ethnicities, and at multiple sites strongly supports a genetic predisposition in the development of keloid phenotype [9, 71]. Certainly, the risk of KD occurrence is higher in genetically susceptible individuals (Bayat et al. $[8,12,16])$. In addition to that, recur- 
rence rate (50\%) is also higher in the African population with family history having positive keloid cases [9]. The linkage loci of KD were initially found to be on chromosomes $2 \mathrm{q} 23$ and $7 \mathrm{p} 11$ by Marneros et al. [72], but no putative gene target was further identified.

Single-nucleotide polymorphisms (commonly found to be useful genetic markers in various association studies) may also confer a risk for keloid disease development, such as PTEN (The phosphatase and tensin homolog) gene polymorphisms at rs2299939, rs17431184, rs555895, and rs701848) were found significantly related with high risk of keloid development in Chinese Han population. In addition, it was found that $\mathrm{CC}$ genotype from rs2299939 appeared as a risk factor in keloid patients as compared to ACTC haplotype prevalence in population, which seems protective factor against keloid formation $[55,56]$.

The GWAS (genome-wide association study) identified three keloid susceptibility loci (rs873549 at 1q41, rs8032158 at 15p21.3 and rs940187 and rs1511412 at 3q22.3) in a Japanese population. Furthermore, an association study of these susceptibility loci was also investigated in keloid patients from Chinese Han population. The SNPs 1q41 (rs873549, and rs1442440,) and 15q21.3 (rs2271289 present in NEDD4) revealed significant association with keloid in the Chinese Han population. In addition, AG haplotype was identified as risk factor whereas, GA and AA haplotypes appeared as protective factors from rs1442440 and rs873549 SNPs. It is also suggested that $15 \mathrm{q} 21.3$ and $1 \mathrm{q} 41$ loci shows genetic association and predisposition for keloid formation in Japanese and Chinese Han populations [116].

Predisposing genes also showed linkage association with keloid susceptibility genes. A study conducted in a selected Han Chinese keloid pedigree, mapped to the region about $1 \mathrm{Mbp}$ on chromosomes 10q23.31, between Fas gene marker D10S1765 and D10S1735, provides the first genetic evidence of a predisposing Fas gene linkage association with keloid susceptibility genes [22].

Another genome-wide association research study (keloid cases $=824$, Healthy cases $=3205$ ) found strong association of keloid cases with four more SNP loci present at three chromosomal locations (3q22.3-23, 1q41, and $15 \mathrm{q} 21.3$ ) in a Japanese population. It was found that SNP rs873549 at chromosome 1 showed the most significant association with keloid cases [76].

The linkage between the susceptibility locus (18q21.1, SMAD, and PIAS2) to keloid and two loci, 18q21.1and $15 \mathrm{q} 22.31-\mathrm{q} 23$, was also investigated through pedigree linkage analysis in a five-generation Han Chinese keloid family. Seven critical regions of microsatellite markers on chromosomes 18q21.1 and 15q22.31-q23 and were included in analysis. Out of the seven markers, only two (D18S460, D18S467) showed linkage to the disease locus [108]. SMAD genes 3, 6, and 7 are known to be involved in fibrotic disorders, and their association with keloid disease susceptibility was also studied in Jamaican keloid patients. Thirty-five SNPs across these genes were genotyped using time-of-flight mass spectrometry (MALDITOF MS) and iPLEX assay. Linkage disequilibrium (LD) was established between several of the SNPs investigated. These findings indicated that the SMAD SNPs were not significantly associated with high risk of keloid formation in the Jamaican population. This study also highlighted the importance of identification of genetic bio-markers as a candidate such as SMAD, which can be helpful diagnostic, prognostic tool and can provide hope for development of new therapeutics for keloid scar management [15].

Keloid predisposition loci at chromosome $7 \mathrm{p} 11$ was studied in a Chinese population pedigree [21] consisting of 5 affected generations and a total of $32 \mathrm{mem}-$ bers. Four microsatellites on chromosome 7 p11 were selected as the genetic markers. This study provided the first genetic indication that keloid predisposition loci did not locate on chromosome 7p11 in Chinese population, furthermore, it suggested that familial keloid predisposition loci are heterogeneous.

Recently in another research study, analysis was conducted through whole genome sequence data, and identified "Leu401Pro variant" in ASAH1 ( $\mathrm{N}$-acylsphingosine amidohydrolase) gene, that revealed co-segregation pattern with keloid phenotype in a large population of Yoruba family. This genetic variant is known to play a role in tumor formation, inflammation and cell proliferation, which suggested that it may be involve in keloid development through various other mechanisms. This study also found some rare coding variants but their susceptibility for non-syndromic development of keloid is not known [85].

\subsection{Large-Scale Population Single-Nucleotide Polymorphism (SNP)}

Researchers have started to investigate deeper into the human genome by using high-throughput microarray genotyping technologies with an objective to develop high-density SNPs map arrays in families with keloid history. Previously genome-wide case-control association study described three susceptibility loci (i) 1q41, (ii) $3 q 22.3-23$, and (iii) $15 q 21.3$ in association with keloid disease, in a Japanese population [76]. NEDD4 gene present in 15q21.3 chromosomal locus, is involve in up regulation of collagen type 1 and fibronectin, that result in extracellular matrix formation [24].

An independent case-control study was conducted to find correlation between SNPS i: e rs2118610, rs873549, rs2271289, rs1511412) and phenotypes of keloid cases in Chinese Han population. This study revealed that inheritance patterns of four SNPs (particularly SNP rs2271289) 
were dominant in severe keloid cases, in comparison with mild cases and control groups. Similar pattern of association of SNP rs2271289 with keloid cases, appeared in family with no case history of keloids as well as in groups having multiple keloid sites. These associations revealed that SNP rs2271289 is a strong contributing factor and a likely candidate in keloid pathology [114].

Association of FOXL2 gene, keloid and SNP rs1511412 have also been identified in Japanese population [76], but this association wasn't significant in the Chinese Han population [116] may be due to low frequency of this variant. Another SNP rs1511412 showed significant association with FOXL2 gene and keloid cases, which appeared as genetic risk factor for keloid development in various ethnic groups of Asian population [64].

A comprehensive study of familial keloids, based on genetic and clinical parameters, was conducted in mostly African Americans, White, Japanese, and African Caribbean families. Individuals affected with keloids exhibited a variable pattern of expression within the families, for example some family members had minor keloids on earlobes and other had large body areas highly affected with severe keloids. In same family, seven members were identified as unaffected but obligate carriers for keloid phenotype. The genetic analysis revealed an autosomal dominant inheritance pattern along with variable phenotypic expression [71].

\subsection{Gene Expression}

Gene regulation and unique genetic components have also been studied in keloid dermal fibroblasts (KDF). Studies revealed up-/downregulated expression of various genes (-Table 8.1). The specific genes and their differentially regulated expression may have direct implications toward understanding the keloid development [25].

\subsection{MicroRNAs (miRNA)}

MicroRNAs are 21-23 nucleotide molecules, targeting the 3'UTR of mRNA and microRNA deregulation may indicate a potential need for clinical intervention [2]. Role of various miRNAs has been established for activation of fibroblasts. A study reported 32 microRNAs differentially expressed in keloid tissues [63], in which total 23 miRNAs (e.g. miR-4269, miR-21, miR382) were up-regulated and 9 miRNAs (e.g. miR-205, miR-203, miR-200b/c) were down-regulated. These miRNAs are involved in various cellular signaling networks particularly wound- healing, development of scar and collagen synthesis [39]. Various studies revealed that microRNAs play a key regulatory role in keloid fibroblasts, for instance, miR200b was found associated with abnormal proliferation in fibroblasts and miR200c was involved in radiation-induced cell apoptosis pathway $[50,55,56,61,117]$. These microRNAs may be considered potential candidates for therapeutic targets for keloids [33]. Three common miRNAs, has-miR-21, has-miR-199a-5p and has-miR-214 were found in some studies [69, 104, 105] among them, hasmiRNA-21 exhibited variable expression [40]. Comparative expression profiles study of miRNA was further extended and found that, keloid derived fibroblasts have total nine different miRNAs as compared to the normal skin fibroblasts. Out of nine, six were upregulated (hsv1-miR- H7, miR-320c, miR-31- 5p, miR23b-3p, miR-152, miR-30a-5p) and three (miR-143-3p, miR-4328 and miR-145-5p) were down-regulated [54, 66]. Some of the key miRNAs that appear differentially expressed in keloid cells have been assessed in more detail the table below (-Table 8.2).

\subsection{Long noncoding RNA (IncRNA)}

Long noncoding RNA, remains uncovered with respect to their association with keloid pathology. The advanced microarray technology was used first time to investigate the keloids in 2015 by Liang et al. group that demonstrated constantly up-regulated (total 1,731) and down-regulated (782) lncRNAs in keloids. In this study, a total of 55 pathways were highlighted: out of which 11 pathways were related to the upregulated transcripts and 44 with downregulated transcripts in keloids. In addition to that, it has been found that the CACNA1G-AS1, as one of the selected lncRNA, may have a potential role in keloid development [58]. The lncRNAs regulating encoding transcripts/genes are considered to participate in Wnt signaling pathway in keloids [95]. The lncRNA H19 stimulate cell proliferation in keloid fibroblasts which reversed by H19 siRNA treatment on keloid fibroblasts [113].

\subsection{Small Interfering RNA (siRNA)}

RNA interference is an evolutionally conserved genetic regulatory mechanism involving inhibition of target gene expression at transcriptional, or translational level, or by degrading the mRNA [101]. Advances in gene silencing [102] provide the opportunity to apply RNA interference technology to uncover the details of molecular mechanisms maintain keloid tissue growth [6]. It is found that $\beta$-catenin expression significantly increased in keloid tissue [18] and has been shown to have a role in the regulation of keloid scarring. Knockdown of 

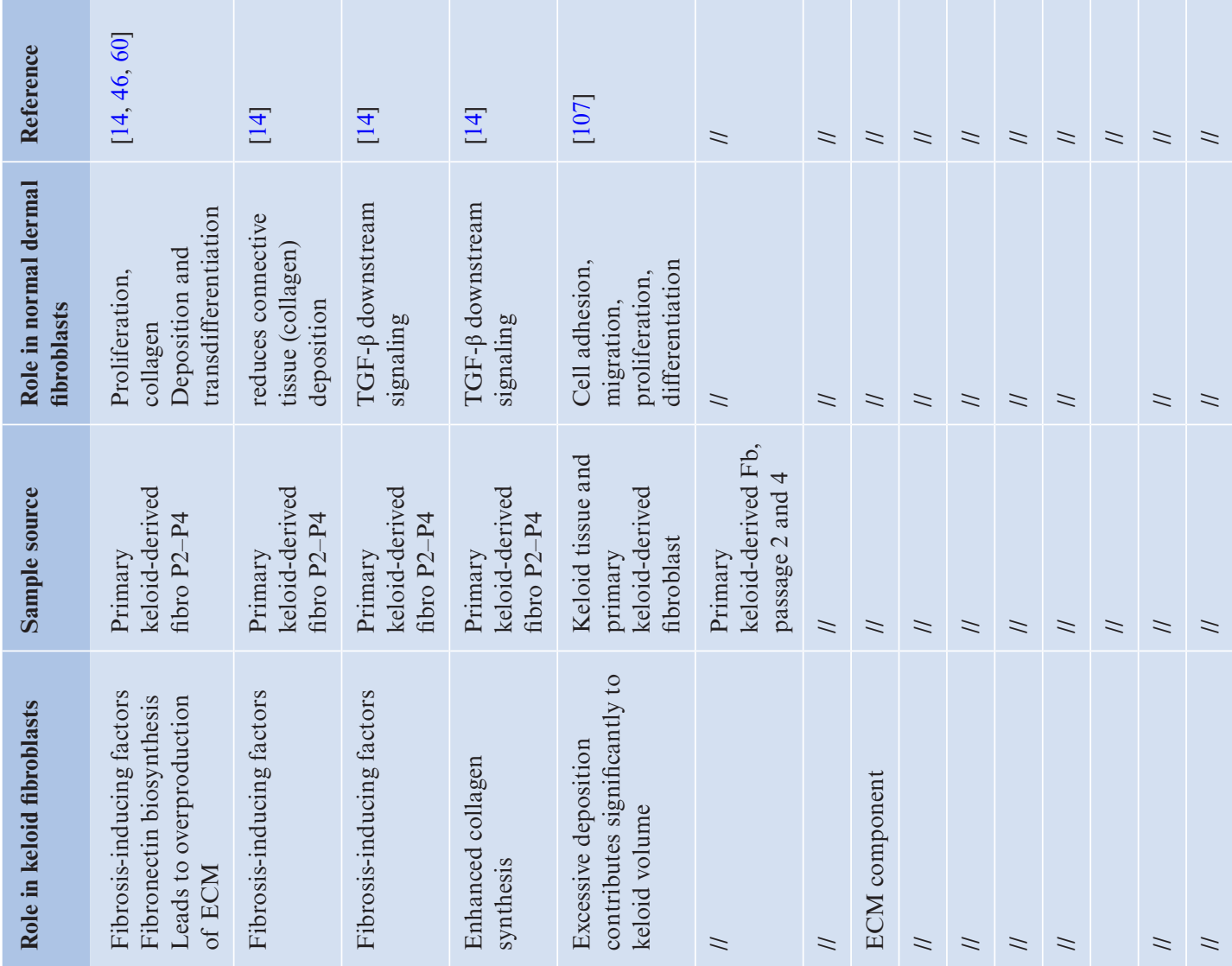

离

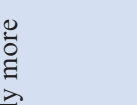

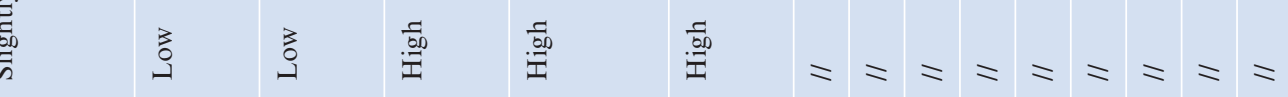

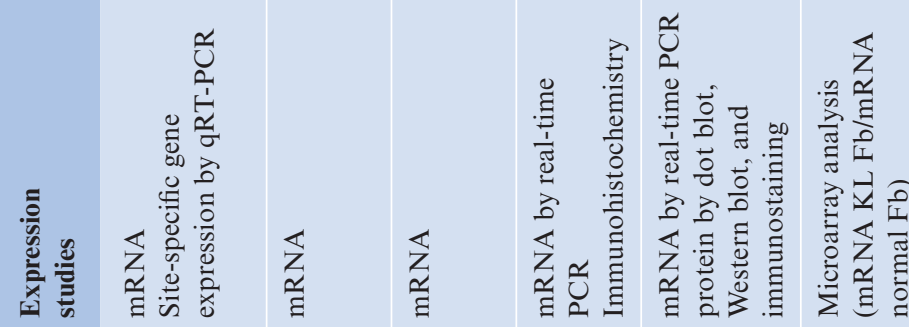

西

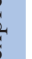
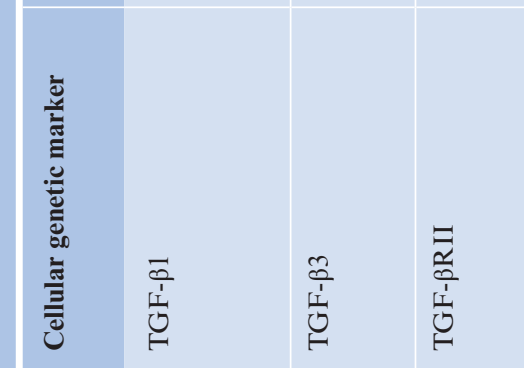


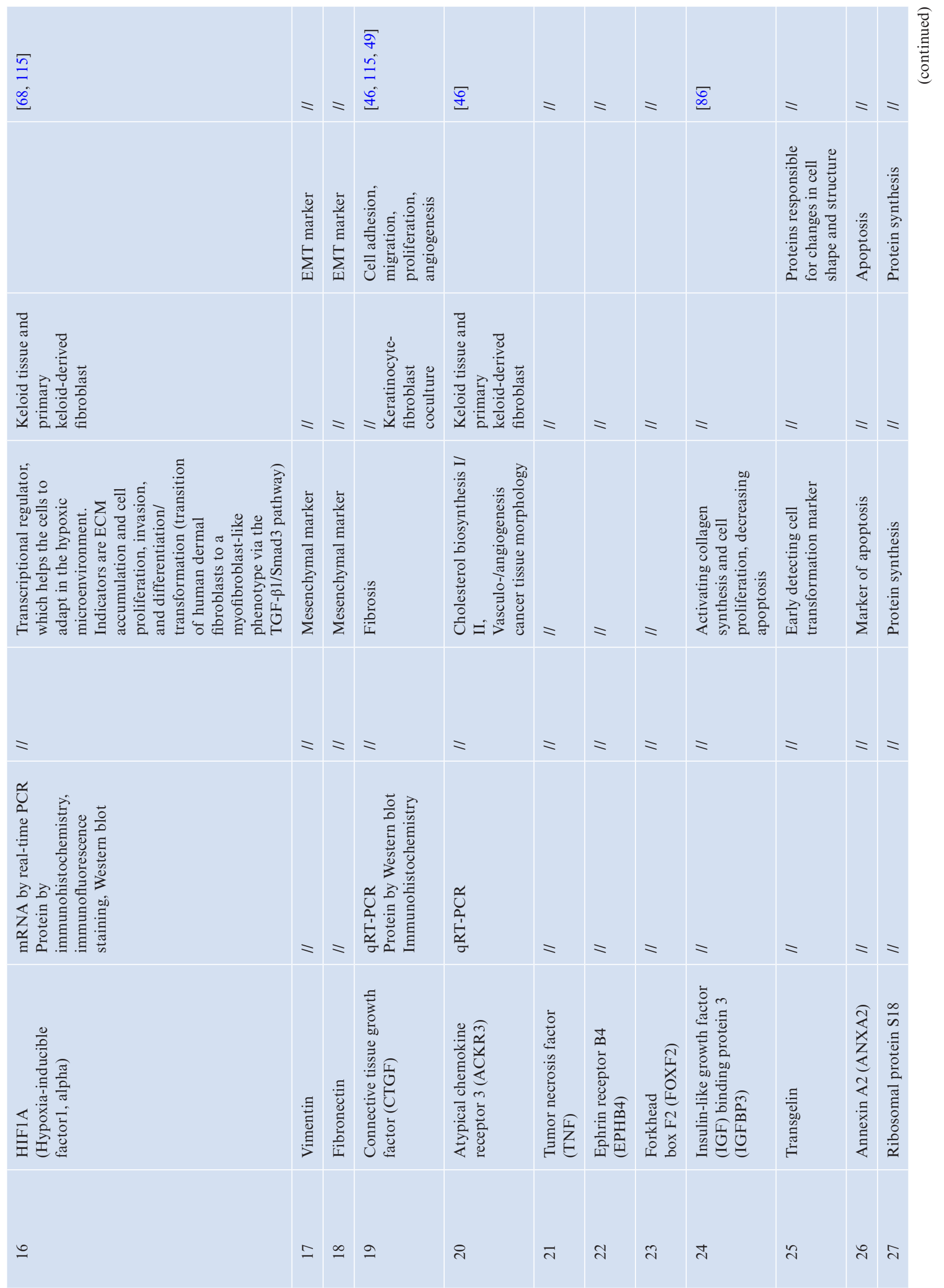




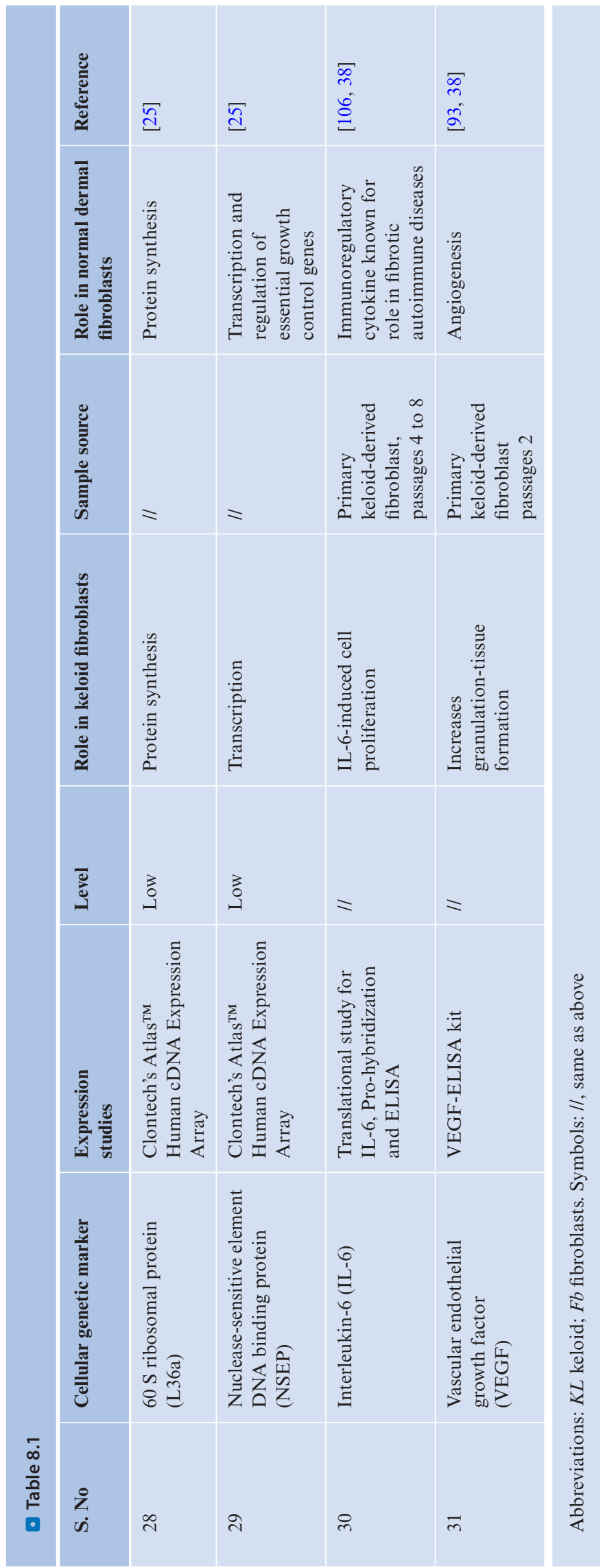


Table 8.2 Differential expression of miRNAs and their effects on keloid fibroblasts

\begin{tabular}{|c|c|c|c|c|}
\hline S. No & Type of microRNA & $\begin{array}{l}\text { Expression level } \\
\text { in keloid } \\
\text { fibroblasts }\end{array}$ & Role in keloid phenotype & Reference \\
\hline 1. & $\operatorname{miR}-7$ & Low & Induce excessive collagen expression & [31] \\
\hline 2. & $\operatorname{miR}-29 a$ & Low & $\begin{array}{l}\text { Collagen I and III expression regulation, } \\
\text { TGF- } \beta / \text { Smad signaling pathway, fibrosis }\end{array}$ & {$[73,41,112]$} \\
\hline 3. & miR-199a & Low & $\begin{array}{l}\text { Influence proliferation of keloid fibroblasts via cell } \\
\text { cycle regulation }\end{array}$ & {$[104,105,109]$} \\
\hline 4. & miR-21 & High & $\begin{array}{l}\text { Stimulate fibroblast proliferation and apoptosis via } \\
\text { P13K/AKT pathway and synthesis of extracellular } \\
\text { matrix }\end{array}$ & {$[62,75,100]$} \\
\hline 5. & miR-196a & High & $\begin{array}{l}\text { Regulates the stabilized elevated expression of } \\
\text { COL1A1 and COL } 3 A 1 \text { genes }\end{array}$ & {$[1,48,54]$} \\
\hline 6. & $\operatorname{miR}-152$ & High & $\begin{array}{l}\text { It promotes keloid fibroblast proliferation and } \\
\text { collagen synthesis }\end{array}$ & {$[54,63]$} \\
\hline
\end{tabular}

$\beta$-catenin/siRNA inhibits cell proliferation and induces arrest in G0/G1 phase of cell cycle. It also induces apoptosis in fibroblasts via down-regulation of cyclin D1 and Wnt2 pathways. Keloid fibroblasts (KFs) overexpress AMF (autocrine motility factor), which acts through RhoA/ROCK1 signaling network, to enhance their cell migration and proliferation. Knocking down AMF/ siRNA significantly reduces the migration as well as proliferation potential of KFs that ultimately reduces keloid size [98].

TIMP-1 and small interfering RNA regulation has an important role in keloid pathology. Generally, it is known that keloid phenotype appears as a result of disproportion between synthesis and degradation of extracellular matrix. There are two main vital components (i) Matrix metalloproteinase (ii) Tissue inhibitors of metalloproteinase, which regulate the process of synthesis degradation and remodeling of ECM. Knockdown of TIMPs (siTIMP-1 or siTIMP-2)/siRNA resulted in suppression of MMP-1/TIMP-1 and MMP-1/TIMP-2 complex molecules but upregulation of MMP-2 and increased collagen type I degradation. KFs also showed increased apoptosis and reduced cell viability [3].

The role of siRNA during TGF- $\beta$-induced regulation of of PTB (Polypyrimidine Tract-Binding Protein) in keloid pathophysiology has been demonstrated recently [43]. It is a splicing regulator and known to play an important role in tumor cell proliferation, invasion and metastasis. TGF- $\beta 1$ stimulation caused over expression of PTB along with its upstream regulatory component (C-MYC) in keloid derived fibroblasts, resulting in dysregulation of alternative splicing events, leads to enhanced fibroblast proliferation and deposition of fibronectin in keloid. PTB/siRNA knockdown shift the alternative splicing of RTN4 and USP, and caused significant reduction in fibroblasts proliferation and deposition of COL3A1 and FN1, that resulting in the fast regression of keloid tissues.

Silencing the Smad2 (Sma and Drosophila mothers against decapentaplegic homolog 2) downregulate the TGF- $\beta$-induced synthesis of procollagen, in keloid derived fibroblasts [35]. The role of siRNA during Smad3 (Sma and Drosophila mothers against decapentaplegic homolog 3)-induced TGF- $\beta$ signaling in keloid pathogenesis has been studied. Smad3 is recently characterized as an intracellular effector of TGF- $\beta$ signaling pathway. TGF- $\beta$ participate as key component in fibrotic pathology by stimulating keloid fibroblasts to synthesize extracellular matrix excessively, including collagen I and III. The knockdown of Smad3/siRNA expression caused significantly and uniquely decrease in types I and III procollagen level. Thus Smad3 is thought to play a significant role in the TGF- $\beta$-induced keloid fibrosis [101].

Keloid derived fibroblasts over expressed NLRC5 (NOD-like receptor family CARD domain containing 5) belongs to the family of nucleotide-binding domain and leucine-rich repeat. It has been shown that silencing of NLRC5 results inhibition of proliferation and expression of ECM in keloid derived fibroblasts via inhibition of TGF- $\beta 1 /$ Smad signaling network, suggesting potential therapeutic target keloids [67]. Increased expression of Stat3 (signal transducer and activator of transcription 3) was also found in keloid tissue. Stat3 is a latent transcription factor activated under the stimulation of various growth factors and cytokines during wound- 
healing process. Short interfering RNA inhibited its expression and subsequent phosphorylation and resulted in reduction of collagen synthesis, cell proliferation and migration in keloid derived fibroblasts, hence suggesting another therapeutic candidate for the treatment of keloids [59].

Keloid fibroblasts characteristically showed overexpression of collagen and PAI-1. Short interfering RNA targeted treatment results in reduction the collagen deposition, which showed that PAI-1-targeted siRNA interference may offer therapeutic alternative in keloid formation [99]. Another study showed that silencing of PAI-1 caused significant reduction in keloid volume up to $28 \%$ in fourth week. It also decreased the synthesis of collagen I and III and resulted in shrinkage of keloid tissue mass [96].

VEGF (vascular endothelial growth factor) plays vital roles in the regulation of inflammation and angiogenesis during wound-healing process. The role of vector-based RNAi (shRNA) for inhibition of VEGF expression in keloid fibroblasts has been studied. siRNA sequences (clone of three potential short interfering RNA sequences) were used to silence the VEGF gene in keloid fibroblasts that resulted in significantly inhibited VEGF gene expression and fibroblasts growth. In addition, the expression of plasminogen activator inhibitor-1 (PAI-1) was also downregulated. This study provides the insight about the modulation of VEGF production as a potential therapeutic strategy for keloid [111].

Silencing by HIF-1 $\alpha$ siRNA in keratinocytes resulted in decreased expression levels of fibronectin and vimentin, whereas ZO-1 and E-cadherin expression levels were restored. This indicated that HIF-1 $\alpha$ stimulation can regulate the respective mesenchymal changes, caused by hypoxia in the keloid derived keratinocytes during keloid development [68].

Knockdown of PAI-2, Hsp27, $\alpha 2 \beta 1$-integrin/siRNA also cause significant reduction in ECM deposition, cell anchorage, and mobility in keloid derived fibroblasts [94]. Hsp70/siRNA and Hsp47-shRNA knockdown decreased collagen synthesis in keloid derived fibroblasts $[20,90]$. hTERT gene regulates telomere length homeostasis and influences cell cycle of fibroblasts. Knockdown of hTERT-siRNA in keloid fibroblasts was shown to reduce telomere length and fibroblast growth [87].

The role of siRNA in apoptosis of keloid fibroblasts has also been investigated. Keloids exhibited increased reactive oxygen species (ROS) production and disrupted apoptosis mechanisms. ROS plays an important role in the induction of apoptosis under pathological conditions. Cellular defense mechanisms against oxidative stress and apoptosis are regulated by nuclear factor erythroid 2-related factor 2 (Nrf2) through activation of B-cell lymphoma 2 (Bcl-2) protein. Transfection of fibroblasts with the Nrf2-specific siRNA resulted in increased apoptosis and decreased cell viability [53]. NRG1/ErbB2/Src/PTK2 signaling pathway in fibroblast migration and the role of siRNA have been investigated in keloid development. Keloid fibroblasts exhibit upregulation of the polypeptide growth factor neuregulin-1 (NRG1) and receptor tyrosine-protein kinase erbB-2 (ErbB2) oncogene that contributes to altered cytokine expression profiles, increased Src and protein tyrosine kinase 2 (PTK2/FAK) gene expression, and migration in keloid fibroblast. siRNA knockdown of ErbB2 gene resulted in reduced migration and Src/PTK2 expression but didn't affect the NRG/ErbB2/Src/PTK2 network, revealing the possibility that this network may affect migrating potential of keloid fibroblasts indirectly [47]. Therefore, siRNA silencing on various targeted mechanisms such as Smad2,3-TGF- $\beta$, HIF-1 $\alpha$-EMT, PAI-1-VEGF production, and NRG1/ ErbB2/Src/PTK2 signaling pathway in keloid pathogenesis, proposes that their production can be modulated by using siRNA based regulation, and this strategy seems promising candidate for keloid therapeutics.

\subsection{Microarray Analysis}

Various advanced molecular biology techniques such as PCR, cDNA approaches, cloning, whole genome sequencing provides the huge platform to investigate the differentially regulated genes in term of microarray analysis from variety of biological samples [70]. Functional genomic provides a tool to probe and monitor the genetic interactions [27]. Complex pattern of genotypic differences and respective multiple fibrosisrelated pathways in keloid fibroblasts have been studied by microarray approach. Comparative Affymetrixbased microarray analysis was carried out on keloid fibroblast RNA. Approximately 500 genes were found differentially regulated out of total the total 38,000 genes observed. Interestingly, study also revealed that increase in expression of various IGF-binding protein and related protein in comparison with set of protein related to Wnt signaling pathway, who exhibited decrease in expression [91]. Total 2,215 differentially expressed genes (DEGs) have been found in comparative analysis of after and before normal wound, and surprisingly total 3,161 DEGs have been identified in keloid-prone individuals. Among those genes, only 513 genes were related to normal individuals, total set of 1,449 genes were found specifically related to keloid phenotype. Moreover, hierarchical distribution of differentially expressed keloid-specific genes resulted into two distinct clusters. Further probing into keloid-specific pathways revealed 24 pathways linked with differentially activated genes. Most importantly, some other vital signaling pathways like NOTCH, MAPKs, TLRs and insulin regulation, have also been found altered during post-wounding analysis in keloid prone individuals. Furthermore, Genetic association network analysis 
revealed, divergent gene expression profile of key genes that contribute in cytokines signaling pathways [79, 83].

\subsection{Epigenetics}

Study of inheritable characteristics of genome that doesn't affect the genetic sequences but only gene function, comes under the term of epigenetics. It is also known to contribute significantly in regulation of various gene expressions. Recently, there is further extension to this terminology that is epigenetic modification, which is currently being applied to get comprehension of molecular aspects of keloid pathology. This study revealed that there are some evidences pointing the involvement of epigenetic changes/modifications triggering the constant activation of fibroblasts in keloid [30]. These epigenetic alterations include changes in microRNAs, DNA methylation as well as histone modifications. These three event are well known crucial events that involve in early cellular growth, differentiation and development, hence these aspects of molecular features have also been included as an important candidate for investigations to understand their role/associations in keloid pathology [28]. Recent studies are coming up with findings about the epigenetic mechanisms that may contribute in keloid formation [42].

\subsubsection{Methylation}

DNA methylation is the well-known aspect of epigenetic modification [103]. It has been hypothesized that DNA methylation is responsible to maintain the myofibroblats transformation of fibroblasts during the process of fibrosis in wound healing events, this modification set the basis for deviation from normal wound-healing mechanism. Gene expression profile acquired by myofibroblasts is significantly differ from fibroblasts $[81,97]$. Therefore it is crucial to understand respective epigenetic modifications that resulted in acquiring highly differentiated gene expression profile in my myofibroblasts that will help to trace the respective network leading to fibrotic phenotype in keloids [77]. Previous research study found that keloid fibroblasts showed alternations in DNA methylation [84]. Involvement and significance of epigenetic modification in keloid pathology has been revealed in recent study, that showed reversal of expression profile in TGF- $\beta 1$, phosphor-smad2, 3 (down-regulation) and smad7 (up-regulation) by the treatment of 5-aza-dC (5-aza-2 deoxycytidine), which is an inhibitor of DNA methyltransferase [118].

Expression of DNA methyltransferase 1 (DNMT1) was found $100 \%$ elevated in keloid as compared to the fibroblast (8\%) from normal skin samples [32], suggesting its involvement in keloid scar formation. Furthermore, different DNA methylation patterns have also been studied in keloid vs normal cells and tissue and analyzed via large scale genome profiling using advanced approach (Infinium Human Methylation 450 BeadChip), results explained that 152 unique genes showed total 192 different methylation patterns in promoter region CpGs. Moreover respective gene network analysis, revealed four common hierarchical regulatory networks, consisting of four key regulators, (i) PENK (ii) PRKG2, (iii) pryoxamide (iv) tributyrin, and total 19 intermediate regulatory molecules. This analysis highlighted the involvement of regulatory networks in keloid phenotype development $[36,45]$ and with the development of this study approach in recent research since last five years, methylome of keloid have been characterized as most hypo-methylated rather than hyper-methylated [45].

List of hyper-methylated genes includes CACNB2, ACTR3C, PAQR4, SLCO2B1, C1orf109, LRRC61, AHDC1, FYCO1, CMKLR1 and CCDC34 as compared to hypo-methylated group of genes, which are GHDC, DENND1C, MX2, ANKRD11, SCML4, GALNT3, IFFO1, WIPF1, PPP1R13L and CFH. Recently, further analysis was carried out using bioinformatics approach by applying Ingenuity Pathway Analysis (IPA) software on data set, obtained from keloid samples, revealed some key pathways shows significant association with keloids. These pathways include (i) histidine degradation VI (ii) metastasis signaling pathway of colorectal cancer (iii) phospholipase $\mathrm{C}$ signaling (iv) $\mathrm{P} 2 \mathrm{Y}$ purinergic receptor signaling and (v) Gai signaling pathway [44]. Keloid fibroblasts having multiple genes with differential methylation, exhibited significant difference in expression profile of genes related to fibrosis such as IGFBP5 (IGF/IGF-binding protein 5), JAG1 (Jagged 1), SFRP1 (secreted frizzled-related protein1), MMP3 (matrix mettallopeptidase 3), CTGF (connective tissue growth factor) and DPT (dermatopontin) [84]. These finding support the statement about the involvement of DNA methylation in keloid formation, but needs further extension of research studies to explore respective key changes/modification that leads subsequent stages of development resulted in keloid pathogenesis [36, 44, 45].

\subsubsection{Histone Modifications}

Histone modifications include changes in distal $\mathrm{N}$-amino acids specifically, phosphorylation at Threonine or Serine, ubiquitination at Arginine or Lysine and acetylation at Lysine amino acid. There are some enzyme such as histone deacetylases (HDACs) and acetyltransferases (HATs), which are involve in these modifications, and result in altered gene expression profile [7]. Interestingly, it has been noted that histone deacetylases over expressed 
in keloid tissue. This over expression pattern has also been observed under TGF- $\beta 1$ induced stimulation in normal fibroblasts and murine Swiss $3 \mathrm{~T} 3$ fibroblasts [34]. In vitro research study showed that treating the keloid fibroblasts with HDAC inhibitor resulted in decreased production of collagen [92]. Inhibition of histone acetyltransferases caused anti-fibrotic affects, increased expression of p300 (which is a cofactor, essential for acetylase activity) in fibroblasts (isolated from scleroderma patients samples) [37].

These studies suggest that both DNA methylation and histone modification are crucial to cause differential gene expression profile, exhibited by keloid fibroblasts, furthermore, as such, any sustainable modification responsible to deliver epigenetic changes, can leads towards phenotypic alteration of keloid fibroblasts. This scenario recommending that inhibitors of histone modification can be an important candidate to consider with therapeutic point of view for management of keloid pathology [5, 80, 84].

\subsection{Mutations}

Role of mutations was investigated in a study conducted in keloid cases from a Caucasian population (95 cases). Large scale genome wide analysis in the exon (1-7) and promoter regions showed presence of some novel mutations in Caucasian population [13]. But up till now, none of the gene mutations have been found associated with keloid cases [88]. One in vitro study reported a p53 mutation that was found in keloid fibroblasts from cultured cells [26], that may suggest the role of acquired inheritable gene changes in keloid cells [88].

\subsection{Copy Number Variation}

Copy number variations (CNVs) are known to be associated with various human disorders including skin diseases. Research study conducted in keloid cases from Caucasian population revealed that CNVs found at 11q11, 8p23.1, 19p13.1, 22q13.1, 17q12, and 2q14.3, specifically $6 \mathrm{p} 21.32$ (that contain HLA-DRB5 region) are associated with keloid pathology [89].

\subsection{FISH (Fluorescence In Situ Hybridization)}

Keloid derived fibroblasts exhibited differential phenotypic and genotypic expression as compared to neighboring normal skin fibroblasts. Real-time RT-PCR and proteomics tools (2-DAGE, immunoblot analysis, and immunohistochemistry) have been used to investigate these differentially expressed specific set of genes and proteins in keloid derived fibroblasts. Proteomic analysis revealed that there are sixteen different spots which differentiate keloid fibroblasts from normal fibroblasts, among all, Hsp70 was most up-regulated protein in keloid derived fibroblasts. These results were also validated by immunohistochemical and western blot analysis conducted on keloid vs normal skin tissue. This study indicated that Hsp70 overexpression may be associated with keloid pathology and its inhibition can be studied for therapeutic purpose [52].

\subsection{Conclusions}

Keloids are benign dermal tumors that develop as a result of a dysregulated cutaneous wound-healing process. Several research findings support the idea that there is an association between various genetic elements such as linkage, autosomal-dominant, oligo-genic or additive inheritance in families and keloid development, predominantly in people of African and Asian descent. In addition to that, differential gene expression studies in families and keloid fibroblasts indicate heterogeneous genetic events, revealing complexity of underlying genetic basis of keloids. Therefore, it's quite obvious that single gene phenomena is not a possible causative factor for keloid formation. To address this complexity, a likely scenario may involve the understanding of genetic pathway interactions including environmental factors, healing mechanisms, wound matrix degradation, and immunologic response.

\section{Take-Home Messages}

1. Keloid is a complex skin pathology with varied susceptibilities and ethnicities. This disease is a clinical challenge because it lacks effective treatment and often recurs after excision.

2. Well-defined comprehensive mode of inheritance is still not known because of insufficient genetic investigations.

3. HLA system represents the highest level of diversity of any functional genetic association with keloid disease.

4. Recent advanced approaches like high-throughput microarray facilitating the genetics and epigenetic investigations may be helpful in understanding the underlying complex basis of keloid formation.

5. There could be a possibility to identifying potential candidate set of genetic markers for diagnostic or prognostic purpose.

6. There is need to uncover the specific biological mechanism and respective signaling networks of keloid fibroblasts. 
Acknowledgments This study was supported by the National Research Foundation and the South African Medical Research Council grants.

\section{Further Readings/Additional Resources}

N. Jumper, T. Hodgkinson, R. Paus, A. Bayat. Site-specific gene expression profiling as a novel strategy for unravelling keloid disease pathobiology. PLoS ONE. 12(3):e0172955. https://doi. org/10.1371/journal.pone.0172955.

Tabib T, Morse C, Wang T, Chen W, Lafyatis R. SRP2/DPP4 and FMO1/LSP1 Define major fibroblast populations in human skin. J Invest Dermatol. 2018;138(4):802-10. https://doi. org/10.1016/j.jid.2017.09.045

Sun HJ, Meng XY, Hu CT. MicroRNA-200c inhibits cell proliferation and collagen synthesis in human keloid fibroblasts via TGF- $\beta /$ Smad pathway. Chinese J Aesthet Med. 2012;21: $1539-42$.

Xue Z, Lan D, Ning S, Ran L. miR-183 inhibits connective tissue growth factor (CTGF) production in TGF- $\beta 1$-treated keloid fibroblasts in vitro. Int J Clin Exp Pathol. 2017;10(6):6425-34.

\section{References}

1. Adhyatmika A, Putri KS, Beljaars L, Melgert BN. The elusive antifibrotic macrophage. Front Med. 2015;2:81.

2. Ambros V. The functions of animal micrornas. Nature. 2004:431:350-5.

3. Aoki M, Miyake K, Ogawa R, Dohi T, Akaishi S, Hyakusoku H, Shimada T. siRNA knockdown of tissue inhibitor of Metalloproteinase- 1 in keloid fibroblasts leads to degradation of collagen type I. J Invest Dermatol. 2014;134:818-26.

4. Ashcroft KJ, Syed F, Arscott G, Bayat A. Assessment of the influence of HLA class I and class II loci on the prevalence of keloid disease in Jamaican afro-Caribbeans. Tissue Antigens. 2011;78(5):390-6.

5. Awakura Y, Nakamura E, Ito N, Kamoto T, Ogawa O. Methylation-associated silencing of SFRP1 in renal cell carcinoma. Oncol Rep. 2008;20(5):1257-63.

6. Bagabir R, Syed F, Paus R, Bayat A. Long-term organ culture of keloid disease tissue. Exp Dermatol. 2012;21(5):376-81.

7. Bassett SA, Barnett MP. The role of dietary histone deacetylases (HDACs) inhibitors in health and disease. Nutrients. 2014;6(10):4273-301.

8. Bayat A, Arscott G, Ollier WER, Ferguson MWJ, Mc Grouther DA. Description of site specific morphology of keloid phenotypes in an Afrocaribbean population. Br J Plast Surg. 2004;57(2):122-33.

9. Bayat A, Arscott G, Ollier WER, Mc Grouther DA, Ferguson MWJ. Keloid disease: clinical relevance of single versus multiple site scars. Br J Plast Surg. 2005;58(1):28-37.

10. Bayat A, Bock O, Mrowietz U, Ollier WE, Ferguson MW. Genetic susceptibility to keloid disease and transforming growth factor beta 2 polymorphisms. Br J Plast Surg. 2002; 55(4):283-6.

11. Bayat A, Bock O, Mrowietz U, Ollier WE, Ferguson MW. Genetic susceptibility to keloid disease and hypertrophic scarring: transforming growth factor betal common polymorphisms and plasma levels. Plast Reconstr Surg. 2003;111(2): 535-43.. discussion 544-6

12. Bayat A, Bock O, Mrowietz U, Ollier WE, Ferguson MW. Genetic susceptibility to keloid disease: transforming growth factor beta receptor gene polymorphisms are not associated with keloid disease. Exp Dermatol. 2004;13(2):120-4.

13. Bayat A, Walter JM, Bock O, Mrowietz U, Ollier WER, Ferguson MWJ. Genetic susceptibility to keloid disease: mutation screening of the TGF- $\beta 3$ gene. Br J Plast Surg. 2005;58: 914-21.

14. Bock O, Yu H, Zitron S, Bayat A, Ferguson MWJ, Mrowietz U. Studies of transforming growth factors Beta 1-3 and their receptors I and II in fibroblast of keloids and hypertrophic scars. Acta Derm Venereol. 2005;85:216-20.

15. Brown JJ, Ollier W, Arscott G, Ke X, Lamb J, Day P, Bayat A. Genetic susceptibility to keloid scarring: SMAD gene SNP frequencies in afro-Caribbeans. Exp Dermatol. 2008;17(7):610-3.

16. Brown JJ, Bayat A. Genetic susceptibility to raised dermal scarring. Br J Dermatol. 2009;161(1):8-18.

17. Brown JJ, Ollier WE, Thomson W, Bayat A. Positive association of HLA-DRB $1 * 15$ with keloid disease in Caucasians. Int $\mathbf{J}$ Immunogenet. 2008;35(4-5):303-7.

18. Cai Y, Zhu S, Yang W, Pan M, Wang C, Wu W. Downregulation of $\beta$-catenin blocks fibrosis via Wnt2 signaling in human keloid fibroblasts. Tumor Biol. 2017;39(6):1-8.

19. Charron D. HLA, immunogenetics, pharmacogenetics and personalized medicine. Vox Sang. 2011;100(1):163-6.

20. Chen JJ, Jin PS, Zhao S, Cen Y, Liu Y, Xu XW, Duan WQ, Wang HS. Effect of heat shock protein 47 on collagen synthesis of keloid in vivo. ANZ J Surg. 2011;81(6):425-30.

21. Chen Y, Gao JH, Liu XJ, Yan X, Song M. Linkage analysis of keloid susceptibility loci on chromosome $7 \mathrm{p} 11$ in a Chinese pedigree. Nan Fang Yi Ke Da Xue Xue Bao. 2006;26(5): 623-5. 637

22. Chen Y, Gao JH, Yan X, Song M, Liu XJ. Location of predisposing gene for one Han Chinese keloid pedigree. Chin J Plast Surg. 2007;23(2):137-40.

23. Choo SY. The HLA system: genetics, immunology, clinical testing, and clinical implications. Yonsei Med J. 2007;48(1): $11-23$.

24. Chung S, Nakashima M, Zembutsu H, et al. Possible involvement of NEDD4 in keloid formation; its critical role in fibro blast proliferation and collagen production. Proc Jpn Acad Ser B Phys Biol Sci. 2011;87:563-73.

25. Cohly HHP, Scott H, Ndebele K, Jenkins JK, Angel MF. Differential gene expression of fibroblasts: keloid versus normal. Int J Mol Sci. 2002;3:1162-76.

26. De Felice B, Garbi C, Santoriello M, Santillo A, Wilson RR. Differential apoptosis markers in human keloids and hypertrophic scars fibroblasts. Mol Cell Biochem. 2009;327(1-2):191201. https://doi.org/10.1007/s11010-009-0057-x.

27. De Felice B, Garbi C, Wilson RR, Santoriello M, Nacca M. Effect of selenocystine on gene expression profiles in human keloid fibroblasts. Genomics. 2011;97(5):265-76.

28. Dwivedi RS, Herman JG, McCaffrey TA, Raj DS. Beyond genetics: epigenetic code in chronic kidney disease. Kidney Int. 2011;79(1):23-32.

29. Dyal CM. Investigation of predictive factors in keloid fortmation. Yale Medicine Thesis Digital Library. 1989;2547. http:// elischolar.library.yale.edu/ymtdl/2547.

30. Egger G, Liang G, Aparicio A, Jones PA. Epigenetics in human disease and prospects for epigenetic therapy. Nature. 2004;429(6990):457-63.

31. Etoh M, Jinnin M, Makino K, Yamane K, Nakayama W, Aoi J, Honda N, Kajihara I, Makino T, Fukushima S, Ihn H. microRNA-7 down-regulation mediates excessive collagen expression in localized scleroderma. Arch Dermatol Res. 2013;305:9-15. 
32. Qipa EY, Hengshu Z. The expression of DNMT1 in pathologic scar fibroblasts and the effect of 5-aza-2-Deoxycytidine on cytokines of pathologic scar fibroblasts. Wounds. 2014;26: 139-46.

33. Feng J, Xue S, Pang Q, Rang Z, Cui F. miR-141-3p inhibits fibroblast proliferation and migration by targeting GAB1 in keloids. Biochem Biophys Res Commun. 2017;490:302-8.

34. Fitzgerald O'Connor EJ, Badshah II, Addae LY, Kundasamy P, Thanabalasingam S, Abioye D, Soldin M, Shaw TJ. Histone deacetylase 2 is upregulated in normal and keloid scars. J Invest Dermatol. 2012;132:1293-6. https://doi.org/10.1038/jid.2011.432.

35. Gao Z, Wang Z, Shi Y, Lin Z, Jiang H, Hou T, Wang Q, Yuan $\mathrm{X}$, Zhao Y, Wu H, Jin Y. Modulation of collagen synthesis in keloid fibroblasts by silencing Smad2 with siRNA. Plast Reconstr Surg. 2006;118(6):1328-37.

36. Garcia-Rodriguez L, Jones L, Chen KM, Datta I, Divine G, Worsham MJ. Causal network analysis of head and neck keloid tissue identifies potential master regulators. Laryngoscope. 2016;126:E319-24.

37. Ghosh AK, Varga J. The transcriptional coactivator and acetyltransferase p300 in fibroblast biology and fibrosis. J Cell Physiol. 2007;213:663-71.

38. Giugliano G, Pasquali D, Notaro A, Brongo S, Nicoletti G, D'Andrea F, Bellastella A, Sinisi AA. Verapamil inhibits interleukin-6 and vascular endothelial growth factor production in primary cultures of keloid fibroblasts. Br J Plast Surg. 2003;56:804-9.

39. Gregory PA, Bert AG, Paterson EL, Barry SC, Tsykin A, Farshid G, Vadas MA, Khew-Goodall Y, Goodall GJ. The miR-200 family and miR-205 regulate epithelial to mesenchymal transition by targeting ZEB1 and SIP1. Nat Cell Biol. 2008;10:593-601.

40. Guo XR, Liang J, Huang RL, Lu L, Jin YD, Luo SJ, Wu ZY. Differential expression of microRNAs in human keloids. Zhongguo Zuzhi Gongcheng Yanjiu. 2012;16:9370-5.

41. He Y, Huang C, Lin X, Li J. MicroRNA-29 family, a crucial therapeutic target for fibrosis diseases. Biochimie. 2013;95: 1355-9.

42. He Y, Deng Z, Alghamdi M, Lu L, Fear MW, He L. From genetics to epigenetics: new insights into keloid scarring. Cell Prolif. 2017:e12326.

43. Jiao H, Dong P, Yan L, Yang Z, Lv X, Li Q, Zong X, Fan J, Fu $X$, Liu X, Xiao R. TGF- $\beta 1$ induces polypyrimidine tractbinding protein to alter fibroblasts proliferation and fibronectin deposition in keloid. Sci Rep. 2016;6:38033.

44. Jones LR, Greene J, Chen KM, Divine G, Chitale D, Shah V, Datta I, Worsham MJ. Biological significance of genome-wide DNA methylation profiles in keloids. Laryngoscope. 2017; 127:70-8

45. Jones LR, Young W, Divine G, Datta I, Chen KM, Ozog D, Worsham MJ. Genome-wide scan for methylation profiles in keloids. Dis Markers. 2015;943176.

46. Jumper N, Hodgkinson T, Paus R, Bayat A. Site-specific gene expression profiling as a novel strategy for unravelling keloid disease pathobiology. PLoS One. 2017;12(3):e0172955. https:// doi.org/10.1371/journal.pone.0172955.

47. Jumper N, Hodgkinson T, Paus R, Bayat A. A role for Neuregulin-1 in promoting keloid fibroblast migration via ErbB2-mediated signaling. Acta Derm Venereol. 2017;97(67):675-84

48. Kashiyama K, Mitsutake N, Matsuse M, Ogi T, Saenko VA, Ujifuku K, Utani A, Hirano A, Yamashita S. miR-196a downregulation increases the expression of type I and III collagens in keloid fibroblasts. J Invest Dermatol. 2012;132:1597-604.

49. Khoo YT, Ong CT, Mukhopadhyay A, Han HC, Do DV, Lim IJ, Phan TT. Upregulation of secretory connective tissue growth factor (CTGF) in keratinocyte-fibroblast coculture contributes to keloid pathogenesis. J Cell Physiol. 2006;208(2):336-43.

50. Kurashige J, Mima K, Sawada G, Takahashi Y, Eguchi H, Sugimachi K, Mori M, Yanagihara K, Yashiro M, Hirakawa K, Baba H, Mimori K. Epigenetic modulation and repression of miR-200b by cancer associated fibroblasts contribute to cancer invasion and peritoneal dissemination in gastric cancer. Carcinogenesis. 2015;36:133-41.

51. Laurentaci G, Dioguardi D. HLA antigens in keloids and hypertrophic scars. Arch Dermatol. 1977;113(12):1726.

52. Lee JH, Shin JU, Jung I, Lee H, Rah DK, Jung JY, Lee WJ. Proteomic profiling reveals upregulated protein expression of Hsp70 in keloids. Biomed Res Int. 2013;2013:1. https://doi. org/10.1155/2013/621538.

53. Lee YJ, Kwon SB, Kim CH, Cho HD, Nam HS, Lee SH, Lee MW, Nam DH, Choi CY, Cho MK. Oxidative damage and nuclear factor Erythroid 2-Related Factor 2 protein expression in normal skin and keloid tissue. Ann Dermatol. 2015;27(5).

54. Li C, Bai Y, Liu H, Zuo X, Yao H, Xu Y, Cao M. Comparative study of microRNA profiling in keloid fibroblast and annotation of differential expressed microRNAs. Acta Biochim Biophys Sin. 2013;45:692-9.

55. Li J, Chen X, Zhou Y, Xie H, Li J, Li J, Su J, Yi M, Zhu W. Risk of keloid associated with polymorphic PTEN haplotypes in the Chinese Han population. Wounds. 2014;26(1):21-7.

56. Li P, He QY, Luo CQ. Overexpression of miR-200b inhibits the cell proliferation and promotes apoptosis of human hypertrophic scar fibroblasts in vitro. J Dermatol. 2014;41:903-11.

57. Li S, Wang M. Chen Dong-ming, bi Hong-sen, Tang Y, Bao Wei-han. Immunogenetic regulation of HLA-DR, DQ, DP and CD1a positive cells in the pathogenesis of keloid and hypertrophic scar. Afr J Microbiol Res. 2012;6(43):7084-8.

58. Liang X, Ma L, Long X, Wang X. LncRNA expression profiles and validation in keloid and normal skin tissue. Int J Oncol. 2015;47:1829-38.

59. Lim CP, Phan T-T, Lim IJ, Cao X. Stat3 contributes to keloid pathogenesis via promoting collagen production, cell proliferation and migration. Oncogene. 2006;25:5416-25.

60. Liu Y, Li Y, Li N, Teng W, Wang M, Zhang Y, Xiao Z. TGF- $\beta 1$ promotes scar fibroblasts proliferation and transdifferentiation via upregulating MicroRNA-21. Sci Report. 2016;6:32231.

61. Lin J, Liu C, Gao F, Mitchel RE, Zhao L, Yang Y, Lei J, Cai J. miR-200c enhances radiosensitivity of human breast cancer cells. J Cell Biochem. 2013;114:606-15.

62. Liu Y, Wang X, Yang D, Xiao Z, Chen X. MicroRNA-21 affects proliferation and apoptosis by regulating expression of PTEN in human keloid fibroblasts. Plast Reconstr Surg. 2014;134:561e-73e.

63. Liu Y, Yang DP, Xiao ZB, Zhang MB. miRNA expression profiles in keloid tissue and corresponding normal skin tissue. Aesthet Plast Surg. 2012;36:193-201.

64. Lu W, Zheng X, Liu S, Ding M, Xie J, Yao X, Zhang L, Hu B. SNP rs1511412 in FOXL2 gene as a risk factor for keloid by meta-analysis. Int J Clin Exp Med. 2015;8(2):2766-71.

65. Lu W-S, Li-Qiong C, Wang Z-X, Li Y, Wang J-F, Feng-Li X, Quan C, He S-M, Yang S, Xue-Jun Z. Association of HLA class I alleles with keloids in Chinese Han individuals. Human Immunol. 2010;71(4):418-22.

66. Luan Y, Liu Y, Liu C, Lin Q, He F, Dong X, Xiao Z. Serum miRNAs signature plays an important role in keloid disease. Curr Mol Med. 2016;16:504-14.

67. Ma HL, Zhao XF, Chen GZ, Fang RH, Zhang FR. Silencing NLRC5 inhibits extracellular matrix expression in keloid fibroblasts via inhibition of transforming growth factor-b1/Smad signaling pathway. Biomed Pharmacother. 2016;83: $1016-21$. 
68. Ma X, Chen J, Xu B, Long X, Qin H, Zhao RC, Wang X. Keloid-derived keratinocytes acquire a fibroblast-like appearance and an enhanced invasive capacity in a hypoxic microenvironment in vitro. Int J Mol Med. 2015;35:1246-56. https://doi. org/10.3892/ijmm.2015.2135.

69. Makino K, Jinnin M, Hirano A, Yamane K, Eto M, Kusano T, Honda N, Kajihara I, Makino T, Sakai K, Masuguchi S, Fukushima S, Ihn H. The downregulation of microRNA let-7a contributes to the excessive expression of type I collagen in systemic and localized scleroderma. J Immunol. 2013;190: 3905-15.

70. Mantripragada KK, Buckley PG. Diaz de Ståhl T, Dumanski JP: genomic microarrays in the spotlight. Trends Genet. 2004;20:87-94.

71. Marneros AG, Norris JEC, Olsen BR, Reichenberger E. Clinical genetics of familial keloids. Arch Dermatol. 2001;137(11):1429-34.

72. Marneros AG, Norris JEC, Watanabe S, Reichenberger E, Olsen BR. Genome scans provide evidence for keloid susceptibility loci on chromosomes 2q23 and 7p11. J Invest Dermatol. 2004;122(5):1126-32.

73. Maurer B, Stanczyk J, Jungel A, Akhmetshina A, Trenkmann M, Brock M, Kowal-Bielecka O, Gay RE, Michel BA, Distler JH, Gay S, Distler O. MicroRNA-29, a key regulator of collagen expression in systemic sclerosis. Arthritis Rheum. 2010;62:1733-43.

74. McCarty SM, Syed F, Bayat A. Influence of the human leukocyte antigen complex on the development of cutaneous fibrosis: an immunogenetic perspective. Acta Derm Venereol. 2010;90:563-74.

75. Mu SZ, Sun YW, Wang GD. Down-regulation of miR-21 inhibits the HSF cells proliferation and the PI3K/Akt pathways via PDCD4. Chin J Aesthet Med. 2015;24:39-43.

76. Nakashima M, Chung S, Takahashi A, Kamatani N, Kawaguchi T, Tsunoda T, Hosono N, Kubo M, Nakamura Y, Zembutsu H. 2010. A genome-wide association study identifies four susceptibility loci for keloid in the Japanese population. Nat Genet. 2010;42:768-71.

77. Neary R, Watson CJ, Baugh JA. Epigenetics and the overhealing wound: the role of DNA methylation in fibrosis. Fibrogenesis and tissue repair. 2015;8:18.

78. Niessen FB, Spauwen PH, Schalkwijk J, Kon M. On the nature of hypertrophic scars and keloids: a review. Plast Reconstr Surg. 1999;104:1435-58.

79. Onoufriadis A, Hsu CK, Ainali C, Ung CY, Rashidghamat E, Yang HS, Huang HY, Niazi U, Tziotzios C, Yang JC, Nuamah R, Tang MJ, Saxena A, de Rinaldis E, McGrath JA. Time series integrative analysis of RNA sequencing and microRNA expression data reveals key biologic wound healing pathways in keloid-prone individuals. J Invest Dermatol. 2018;138(12): 2690-3.

80. Palii SS, Van Emburgh BO, Sankpal UT, Brown KD, Robertson KD. DNA methylation inhibitor 5-Aza-2'-deoxycytidine induces reversible genome-wide DNA damage that is distinctly influenced by DNA methyltransferases 1 and 3B. Mol Cell Biol. 2007;28(2):752-71.

81. Phan SH. Biology of fibroblasts and myofibroblasts. Proc Am Thorac Soc. 2008;5(3):334-7. https://doi.org/10.1513/ pats.200708-146DR.

82. Rabello FB, Souza CD, Junior JAF. Update on hypertrophic scar treatment. Clinics (Sao Paulo). 2014;69:565-73.

83. Ramos ML, Gragnani A, Masako FL. Microarray as a new tool to study hypertrophic and keloid scarring. Wounds. 2009;21(2):57-63.

84. Russell SB, Russell JD, Trupin KM, Gayden AE, Opalenik SR, Nanney LB, Broquist AH, Raju L, Williams SM. Epigenetically altered wound healing in keloid fibroblasts. J Invest Dermatol. 2010;130(10):2489-96. https://doi.org/10.1038/jid.2010.162.

85. Santos-Cortez RLP, Hu Y, Sun F, Benahmed-Miniuk F, Tao J, Kanaujiya JK, Ademola S, Fadiora S, Odesina V, Nickerson DA, Bamshad MJ, Olaitan PB, Oluwatosin OM, Leal SM, Reichenberger EJ. Identification of ASAH1 as a susceptibility gene for familial keloids. Eur J Hum Genet. 2017;25(10): 1155-61.

86. Satish L, Lyons-Weiler J, Hebda PA, Wells A. Gene expression patterns in isolated keloid fibroblasts. Wound Repair Regen. 2006;14(4):463-70.

87. Shang Y, Yu D, Hao L. Liposome-adenoviral hTERT-siRNA knockdown in fibroblasts from keloids reduce telomere length and fibroblast growth. Cell Biochem Biophys. 2015;72:405-10.

88. Shih B, Bayat A. Genetics of keloid scarring. Arch Dermatol Res. 2010;302(5):319-39.

89. Shih B, Bayat A. Comparative genomic hybridization analysis of keloid tissue in Caucasians suggests possible involvement of HLA-DRB5 in disease pathogenesis. Arch Dermatol Res. 2012;304:241-9.

90. Shin JU, Lee WJ, Tran TN, Jung I, Lee JH. Hsp70 knockdown by siRNA decreased collagen production in keloid fibroblasts. Yonsei Med J. 2015;56(6):1619-26.

91. Smith JC, Boone BE, Opalenik SR, Williams SM, Russell SB. Gene profiling of keloid fibroblasts shows altered expression in multiple fibrosis-associated pathways. J Invest Dermatol. 2008;128(5):1298-310.

92. Spallotta F, Cencioni C, Straino S, Nanni S, Rosati J, Artuso S, Manni I, Colussi C, Piaggio G, Martelli F, Valente S, Mai A, Capogrossi MC, Farsetti A, Gaetano C. A nitric oxide-dependent cross-talk between class $\mathrm{i}$ and iii histone deacetylases accelerates skin repair. J Biol Chem. 2013;288:11004-12.

93. Steinbrech DS, Mehrara BJ, Chau D, Rowe NM, Chin G, Lee T, Saadeh PB, Gittes GK, Longaker MT. Hypoxia upregulates VEGF production in keloid fibroblasts. Ann Plast Surg. 1999;42:514-9.

94. Suarez E, Syed F, Alonso-Rasgado T, Mandal P, Bayat A. Up-regulation of tension-related proteins in keloids: knockdown of Hsp27, $\alpha 2 \beta 1$-Integrin, and PAI-2 shows convincing reduction of extracellular matrix production. Plastic and Reconstructive Surgery. 2013;131(2):158e-73e. https://doi. org/10.1097/PRS.0b013e3182789b2b.

95. Sun XJ, Wang Q, Guo B, Liu XY, Wang B. Identification of skin related lncRNAs as potential biomarkers that involved in Wnt pathways in keloids. Oncotarget. 2017;8:34236-44.

96. Syed F, Bagabir RA, Paus R, Bayat A. Ex vivo evaluation of antifibrotic compounds in skin scarring: EGCG and silencing of PAI-1 independently inhibit growth and induce keloid shrinkage. Lab Investig. 2013;93:946-60.

97. Tao H, Huang C, Yang JJ, Ma TT, Bian EB, Zhang L, Lv XW, Jin Y, Li J. MeCP2 controls the expression of RASAL1 in the hepatic fibrosis in rats. Toxicology. 2011;290(2-3):327-33. https://doi.org/10.1016/j.tox.2011.10.011.

98. Yi T, Jin L, Zhang W, Ya Z, Cheng Y, Zhao H. AMF siRNA treatment of keloid through inhibition signaling pathway of RhoA/ROCK1. Genes \& Diseases. 2018;xx:1-8.

99. Tai-Lan T, Hwu P, Ho W, Yiu P, Chang R, Wysocki A, Benya PD. Adenoviral overexpression and small interfering RNA suppression demonstrate that plasminogen activator Inhibitor-1 produces elevated collagen accumulation in normal and keloid fibroblasts. Am J Pathol. 2008;173(5):1311-25.

100. Wang X, Liu Y, Chen X, Zhang M, Xiao Z. Impact of MiR-21 on the expression of FasL in the presence of TGF-betal. Aesthet Surg J. 2013;33:1186-98.

101. Wang Z, Gao Z, Shi Y, Sun Y, Lin Z, Jiang H, Hou T, Wang Q, Yuan X, Zhu X, Wu H, Jin Y. Inhibition of Smad3 expression 
decreases collagen synthesis in keloid disease fibroblasts. J Plast Reconstr Aesthet Surg. 2007;60(11):1193-9.

102. Watts JK, Corey DR. Silencing disease genes in the laboratory and the clinic. J Pathol. 2011;226(2):365-79.

103. Weisenberger DJ, Velicescu M, Cheng JC, Gonzales FA, Liang $\mathrm{G}$, Jones PA. Role of the DNA methyltransferase variant DNMT3b3 in DNA methylation. Mol Cancer Res. 2004;2: $62-72$.

104. Wu ZY, Lu L, Guo XR, Zhang PH. Identification of differently expressed microRNAs in keloid and pilot study on biological function of miR-199a-5p. Zhonghua Zheng Xing Wai Ke Za Zhi. 2013;29:279-84.

105. Wu ZY, Lu L, Liang J, Guo XR, Zhang PH, Luo SJ. Keloid microRNA expression analysis and the influence of miR$199 \mathrm{a}-5 \mathrm{p}$ on the proliferation of keloid fibroblasts. Genet Mol Res. 2014;13:2727-38.

106. Xue H, McCauley RL, Zhang W. Elevated interleukin-6 expression in keloid fibroblasts. J Surg Res. 2000;89:74-7.

107. Yagi Y, Muroga E, Naitoh M, Isogai Z, Matsui S, Ikehara S, Suzuki S, Miyachi Y, Utani A. An ex vivo model employing keloid-derived cell-seeded collagen sponges for therapy development. J Investig Dermatol. 2013;133:386-93.

108. Yan X, Gao JH, Chen Y, Song M, Liu XJ. Preliminary linkage analysis and mapping of keloid susceptibility locus in a Chinese pedigree. Chinese J Plast Surg. 2007;23(1):32-5.

109. Yang X, Lei S, Long J, Liu X, Wu Q. MicroRNA-199a-5p inhibits tumor proliferation in melanoma by mediating HIF1alpha. Mol Med Rep. 2016;13:5241-7.

110. Zhang G, Jiang J, Luo S, Tang S, Liang J, Yao P. Analyses of CDC2L1 gene mutations in keloid tissue. Clin Exp Dermatol. 2012;37:277-83.

111. Zhang GY, Yi CG, Li X, Zheng Y, Niu ZG, Xia W, Meng Z, Meng CY, Guo SZ. Inhibition of vascular endothelial growth factor expression in keloid fibroblasts by vector-mediated vascular endothelial growth factor shRNA: a therapeutic potential strategy for keloid. Arch Dermatol Res. 2008;300(4):177-84.

112. Zhang GY, Wu LC, Liao T, Chen GC, Chen YH, Zhao YX, Chen SY, Wang AY, Lin K, Lin DM, Yang JQ, Gao WY, Li QF. A novel regulatory function for miR-29a in keloid fibrogenesis. Clin Exp Dermatol. 2016;41:341-5.

113. Zhang J, Liu CY, Wan Y, Peng L, Li WF, Qiu JX. Long noncoding RNA H19 promotes the proliferation of fibroblasts in keloid scarring. Oncol Lett. 2016;12:2835-9.

114. Zhao Y, Liu SL, Xie J, Ding MQ, Lu MZ, Zhang LF, Yao XH, Hu B, Lu WS, Zheng XD. NEDD4 single nucleotide polymorphism rs2271289 is associated with keloids in Chinese Han population. Am J Transl Res. 2016;8(2):544-55.

115. Zhao B, Guan H, Liu J-Q, Zheng Z, Zhou Q, Zhang J, Su L-L, $\mathrm{Hu}$ D-H. Hypoxia drives the transition of human dermal fibroblasts to a myofibroblast-like phenotype via the TGF- $\beta 1 / \mathrm{Smad} 3$ pathway. Int J Mol Med. 2017;39(1):153-9. https://doi. org/10.3892/ijmm.2016.2816.

116. Zhu F, Wu B, Li P, Wang J, Tang H, Liu Y, Zuo X, Cheng H, Ding Y, Wang W, Zhai Y, Qian F, Wang W, Yuan X, Wang J, Ha W, Hou J, Zhou F, Wang Y, Gao J, Sheng Y, Sun L, Liu J, Yang S, Zhang X. Association study confirmed susceptibility loci with keloid in the Chinese Han population. PLoS One. 2013;8(5):e62377.

117. Zhu HY, Bai WD, Li C, Zheng Z, Guan H, Liu JQ, Yang XK, Han SC, Gao JX, Wang HT, Hu DH. Knockdown of lncRNAATB suppresses autocrine secretion of TGF-beta2 by targeting ZNF217 via miR-200c in keloid fibroblasts. Sci Rep. 2016;6:24728.

118. Zou QP, Yang E, Zhang HS. Effect of the methylation enzyme inhibitors of 5-aza-2- deoxycytidine on the TGF-beta/smad signal transduction pathway in human keloid fibroblasts. Chinese J Plast Surg. 2013;29:285-9.

Open Access This chapter is licensed under the terms of the Creative Commons Attribution 4.0 International License (http://creativecommons. org/licenses/by/4.0/), which permits use, sharing, adaptation, distribution and reproduction in any medium or format, as long as you give appropriate credit to the original author(s) and the source, provide a link to the Creative Commons license and indicate if changes were made.

The images or other third party material in this chapter are included in the chapter's Creative Commons license, unless indicated otherwise in a credit line to the material. If material is not included in the chapter's Creative Commons license and your intended use is not permitted by statutory regulation or exceeds the permitted use, you will need to obtain permission directly from the copyright holder.

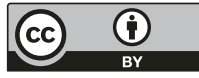

